\title{
$\alpha$-ADRENOCEPTORS MEDIATING POSITIVE INOTROPIC EFFECTS ON THE VENTRICULAR MYOCARDIUM: SOME ASPECTS OF STRUCTURE-ACTIVITY RELATIONSHIP OF SYMPATHOMIMETIC AMINES ${ }^{1}$
}

\author{
M. ENDOH, ${ }^{2}$ H.J. SCHÜMANN, N. KRAPPITZ and B. HILLEN \\ Institute of Pharmacology, University of Essen, D-4300 \\ Essen-Holsterhausen, Germany
}

Accepted November 27, 1975

\begin{abstract}
Abstraet-Experiments were carried out on the isolated papillary muscle of the rabbit in order to further characterize the $\alpha$-adrenoceptors mediating the positive inotropic effect. For this purpose dose-response relations of seven sympathomimetic amines were compared under the influence of $r$-and or $\hat{s}$-adrenolytic drugs. Phentolamine $\left(10^{-\hat{b}} \mathrm{M}\right)$ shifted the lower part of the dose-response curves for norfenephrine, synephrine and epinine as for phenylephrine and adrenaline to the right, while prindolol $\left(10^{-5} \mathrm{M}\right)$ affected only the upper part of the curves. In the presence of both $a-$ and adrenoceptor blocking agents the entire dose-response curves for sympathomimetic amines were shifted in a parallel manner. Noradrenaline affected preferentially 3-adrenoceptors, whereas its effect on $r$-adrenoceptors was so weak that it could be detected only when the neuronal and extraneuronal uptake mechanism of anines were blocked by cocaine $\left(3 \quad 10^{-5} \mathrm{M}\right)$ and corticosterone $\left(4.10^{-5} \mathrm{M}\right)$, respectively. The effect of dopamine was not affected either by phentolamine or by prindolol, but was antagonized by the simultancous application of both is and $j$-adrenoceptor blocking agents. From the present results, it appears that the following relationships are present between the structure of amines and the $n$-adrenoceptor stimulating activity in the heart: (1) $\mathrm{N}$-methylation increases the potency; (2) Alssence of the hydroxyl group either in 3 or in 4 position decreases the intrinsic and, F-adrenoceptor stimulating activities, but increases the r-adrenoceptor stimulating activity.
\end{abstract}

The question of whether or not the positive inotropic response to sympathomimetic amines is mediated via $\alpha$-adrenoceptors in the atrial myocardium is still under discussion: since Govier $(1,2)$ has reported that in the left atrium of the guinea-pig $\alpha$-adrenoceptors are responsible for inducing partly the positive inotropic effect of phenylephrine, adrenaline and noradrenaline, papers supporting as well as contradicting his observations have been presented. In experiments on the left atrium of the rabbit (3-6) as well as of the rat (7) these observations of Govier were confirmed. On the spontaneously beating rabbit atrium, however, the positive inotropic effect of phenylephrine was due to stimulation of $\beta$ - but not of a-adrenoceptors (8).

Consistent with the latter observations, recent experiments in our laboratory demonstrated that only, 3 - not $\alpha$-adrenoceptors mediated the positive inotropic as well as chrono-

This work was supported by the Deutsche Forschungsgemeinschaft

$\because$ Present address: Department of Pharmacology, Tohoku University School of Medicine, Sendai 980 , Japan 
tropic effects of phenylephrine on the left and right atria of the guinea pig and of the rabbit $(9,10)$.

Also in the ventricular myocardium contradictory experimental results are obtained: the positive inotropic effect of phenylephrine was antagonized by the $\alpha$-adrenolytic drug phentolamine in the isolated ventricular strip of the rat (11) and in the isolated perfused heart of the rabbit $(12,13)$, whereas by the 3 -adrenolytic drug propranolol, in the isolated perfused heart of the rat (14) and of the dog (15). Recent studies from our laboratory have shown that in the isolated papilary muscle of the rabbit the $x$-adrenoceptor blocking agent phentolamine shifted the dose-response curves for phenylephrine and adrenaline to the right (16), and abolished the positive inotropic effect of methoxamine and naphazoline (17). According to Furchgott (18), adrenoceptors classified as a type mediate responses which are characterized by a relative potency series in which adrenaline and noradrenaline are highest, phenylephrine somewhat lower, and isoprenaline very low, and by a susceptibility to blockade by a number of the so-called "classical" adrenergic blocking agents (c.g., phentolamine, dihydrocrgotamine, dibenzmine, and the like). In our studies on the rabbit papillary muscle, however, when a relative potency was compared in the presence of the 3-adrenolytic drug prindolol, those of adrenaline and phenylephrine were higher than that of noradrenaline. Furthermore, phentolamine blocked the effect of phenylephrine most effectively, reduced that of adrenaline to a lesser extent, but did not alter the effect of noradrenaline (16). These observations suggest that $\alpha$-adrenoceptors in the rabbit heart may be different in nature from those of other organs.

In order to further characterize a-adrenoceplors mediating the positive inotropic effect in the heart, the effects of seven structurally related sympathomimetic amines, noradrenaline, adrenaline, phenylephrine, norfenephrine, dopamine, epinine and synephrine were compared on the isolated rabbit papillary muscle. Their cffects were analyzed by using the $\alpha$-and 3 -adrenoceptor blocking agents, phentolamine and prindolol, respectively. An attempt was made to determine whether or not a relationship exists between the structure of amines and their $\alpha$-stimulating activity.

\section{MATFRIALS AND METHODS}

Papillary muscles excised from the right ventricle of rabbits of either sex (1.5-2.4 kg) were used. Muscles were mounted in a $20 \mathrm{ml}$ bath containing Krebs-Henseleit solution with $0.057 \mathrm{mM}$ ascorbic acid, and driven electrically by square wave impulses of $5 \mathrm{msec}$-duration and a voltage about $20^{\circ}$, above threshold at a frequency of $1.4 \mathrm{~Hz}$. The bath fluid was aerated with $95^{\circ}, \mathrm{O}_{2}$ and $5 \%, \mathrm{O}_{3}$. Fxperiments were performed at a temperature of $37 \mathrm{C}$. The details of the methods and procedures were described previously (16).

After an equilibration time of 60 min under the resting tension of $0.5 \mathrm{~g}$ submaximally effective concentrations of sympathomimetic amines were administrated twice or threc times until successive responses remained constant. The cumulative dose-response curve for each amine was then determined by adding $0.1 \mathrm{ml}$ of drug solutions. The concentration of drugs in the bath was increased by 0.5 log units until the maximal response was obtained. 
After the maximal response was reached, the preparations were washed out by KrebsHenseleit solution containing phencolamine $\left(10^{-r} \mathrm{M}\right)$ and/or prindolol $\left(10^{-8} \mathrm{M}\right)$ every ten minutes over 60 min. When the developed tension reached the level prior to the determination of the first dose-response curve, the next curve was determined in the same manner in the presence of the blocking agents. The maximal developed tension and the affinity for sympathomimetic amines as determined by $\mathrm{pD}_{2}$-values remained unchanged during the determination of three successive dose-response curves in the absence of blocking agents as previously shown with phenylephrine (16). The intrinsic activities of amines were compared with that of isoprenaline as a standard substance. Doses of isoprenaline which induce the maximal response $\left(3 ; 10^{-}-10^{-\hat{B}} \mathrm{M}\right)$ were applied before and after the determination of the maximal response to each amine. In this series of experiments we started with the concentration of amines which produces $80 \%$ of the maximal response in order to avoid the fading phenomenon observed with phenylephrine (19).

Rescrpine was injected i.v. twice in doses of $1 \mathrm{mg} / \mathrm{kg}$ and $0.5 \mathrm{mg} / \mathrm{kg} 48$ and $24 \mathrm{hr}$ prior to the experiment, respectively. Some experiments were performed in a Krebs-Henseleit solution containing cocaine $\left(3 \times 10^{-5} \mathrm{M}\right)$ and corticosterone $\left(4 \times 10^{-5} \mathrm{M}\right)$ in order to block the neuronal and extraneuronal uptake of the amines (20).

By plotting the dose-response curves of single experiments on semi-logarithmic paper the concentrations ranging from the ED10 to the ED100 were estimated and the means for these concentrations were used to construct the dose-response curve (21). The $\mathrm{pD}_{2}$-value ( - log ED50) was calculated as described by Van Rossum (22). Significant differences of the $\mathrm{pD}_{2}$-values were estimated by means of Student's $t$-test. The test for paired comparison was used when it was applicable. A p-value smaller than 0.05 was considered to be significant.

Drugs used were ( ) )-phenylephrine hydrochloride, ( )-synephrine tartrate, epinine hydrochloride (Boehringer, lngelheim); (-)-adrenaline base, ( - )-noradrenaline base (Hocchst, Frankfurt); ( )-norfenephrine hydrochloride (Bayer, Leverkusen); dopamine hydrochloride (Serva, Hejdelberg); reserpine, phentolamine hydrochloride (Ciba, Basle); (-)-prindolol (Sandoz, Basle); cocaine hydrochloride (Merck, Darmstadt); corticosterone (Fluka, Buchs SG). Stock solutions of amines were prepared in $1 \%$ ascorbic acid and the drug solutions were kept ice-cooled in order to avoid autoxidation. All concentrations are expressed as final bath concentrations in terms of molarities.

\section{RESULTS}

The affinities as determined by the $\mathrm{pD}_{2^{-}}$-values and the intrinsic activities for sympathomimetic amines are given in Table 1. The order of the affinities for the amines were the following: adrenaline $;$ noradrenaline ... phenylephrine $>$ norfenephrine $>$ epinine dopamine ; synephrine. The differences of the $\mathrm{pD}_{2}$-values between either noradrenaline and phenylephrine, or epinine and dopamine were not significant $(P>0.05)$. The same intrinsic activity was seen with adrenaline, noradrenaline, epinine and dopamine. The activities for synephrine, norfenephrine and phenylephrine were significantly smaller than the activity for isoprenaline. 
TABLE 1. The $\mathrm{pD}_{2}$-values and the intrinsic activities of sympathomimetic amines in the isolated rabbit papillary muscle

\begin{tabular}{|c|c|c|}
\hline & $\mathrm{pD}_{2}$-value & Intrinsic activily* \\
\hline Adrenaline & $6.18 \div 0.09(14)^{\text {t.t }}$ & $1.00 \div 0.02(7)$ n.s. \\
\hline Phenylephrine & $5.77 \quad 0.06(28)$ & $0.74,0.03(7)^{* \ldots}$ \\
\hline Synephrine & $4.63-0.06(11)$ & $0.64 \cdot 0.04(6)^{* * * *}$ \\
\hline Epinine & $4.95: 0.05(22)$ & $0.95 \therefore 0.02(7) \mathrm{n} . \mathrm{s}$. \\
\hline Noradrenaline & $5.91: 0.09(10)$ & $0.98-0.02(8)$ n.s. \\
\hline Norfenephrine & $5.17-0.09(10)$ & $0.71 \pm 0.02(4)^{* * * *}$ \\
\hline Dopamine & $4.80 \cdots 0.04(7)$ & $1.02-0.04$ (5)n.s. \\
\hline
\end{tabular}

* Isoprenaline $=1$

** Number of experiments in brackets.

*** $\mathrm{P}<0.005 ;$ n.. . $=$ not significant.

The dose-response curves for sympathomimetic amines in the absence as well as in the presence of phentolanine $\left(10^{-6} \mathrm{M}\right)$ or and prindolol $\left(10^{-8} \mathrm{M}\right)$ are shown in Figs. 1 to 7 . The slopes of the curves under control conditions were similar except that those for epinine (Fig. 4) and dopamine (Fig. 7) were somewhat steeper. Phentolamine shifted substantially the lower part of dose-response curves for adrenaline (Fig. 1), phenylephrine (Fig. 2), norfenephrine (Fig. 3), epinine (Fig. 4) and synephrine (Fig. 5), while prindolol affected chiefly the upper part of these curves. Only in the presence of both adrenergic blocking agents the whole dose-response curves for these amines were shifted to the right in a parallel manner. Different from these amines were noradrenaline (Fig. 6) and dopamine (Fig. 7A). Prindolol

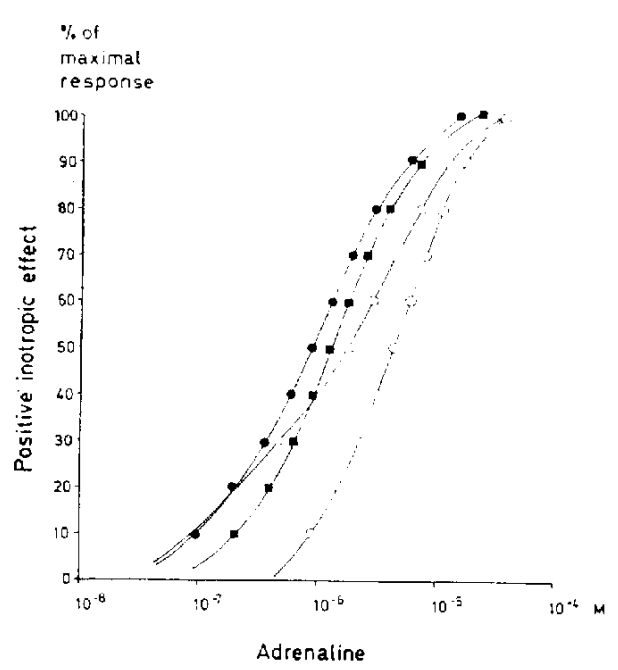

Frg. 1. The positive inotropic effect of adrenaline on the isolated rabbit papillary muscle.

phentolamine $10^{-6} \quad \mathrm{M} \quad(\mathrm{n}=7): \square-\mathrm{i}_{\mathrm{S}}$ : prindolol $10^{-5} \mathrm{M}$ (17 7): - : phentolamine prindolol in:-14).

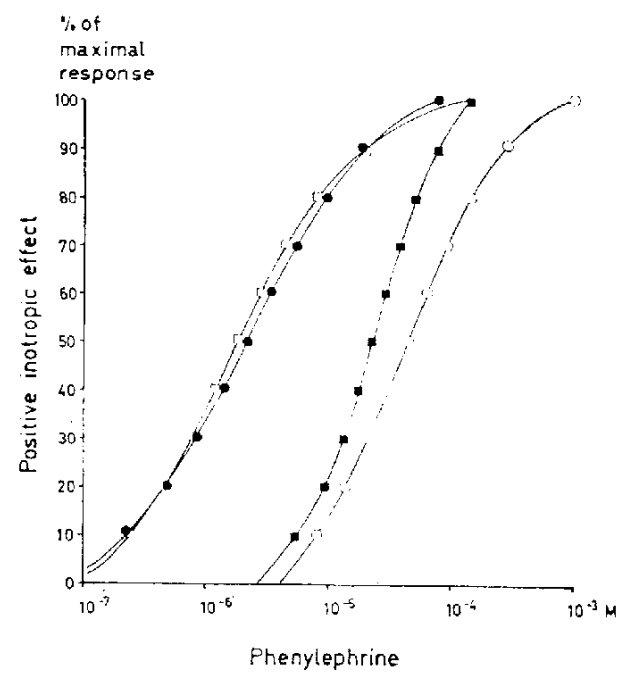

Fici. 2. The positive inotropic effect of phemylephrine on the isolated rabbit papillary muscle. - - control $(n=28)$; phentolamine $10^{\text {: }} \mathrm{M} \quad(n=6): \square-[$ : prindolol $10, M(n-8)$ : : phentolamine prindolol $(n-14)$. 


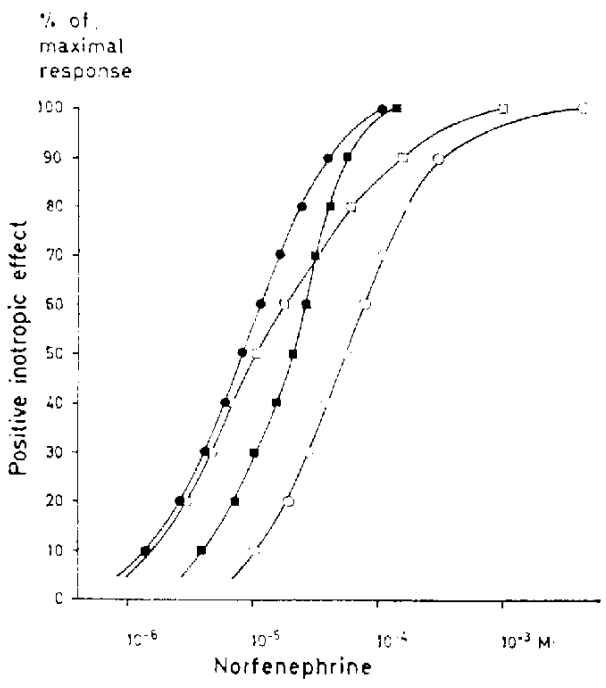

Fici. 3. The positive inotropic elfect of norfenephrine on the isolated rabbit papillars muscle. - control $(n=10)$; phentolamine $10^{-6} \quad \mathrm{M} \quad(\mathrm{n}=-5)$ : prindolol $10^{-9} \mathrm{M}$ (n ... 5): _. tolamine prindolol $(n=10)$.

$\%$ of

maximal

response

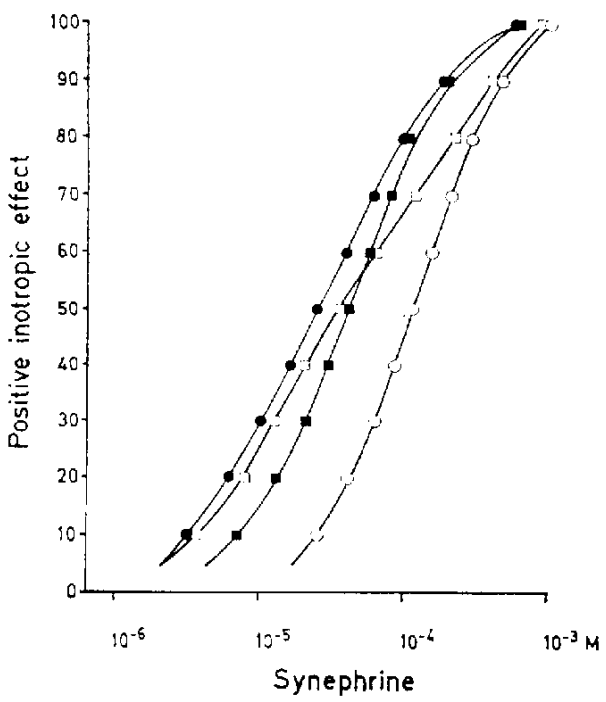

Fiti. 5. The positive inotropic effect of symephrine on the isolaled rabbit papillary muscle.

phentolamine $10^{-\mathrm{i}} \mathrm{M}(\mathrm{n} \cdot 8)$;

prindolol $10^{-4} \mathrm{M}(\mathrm{n}-4)$ : -.- $:$ phentolamine prindolol (n-12).

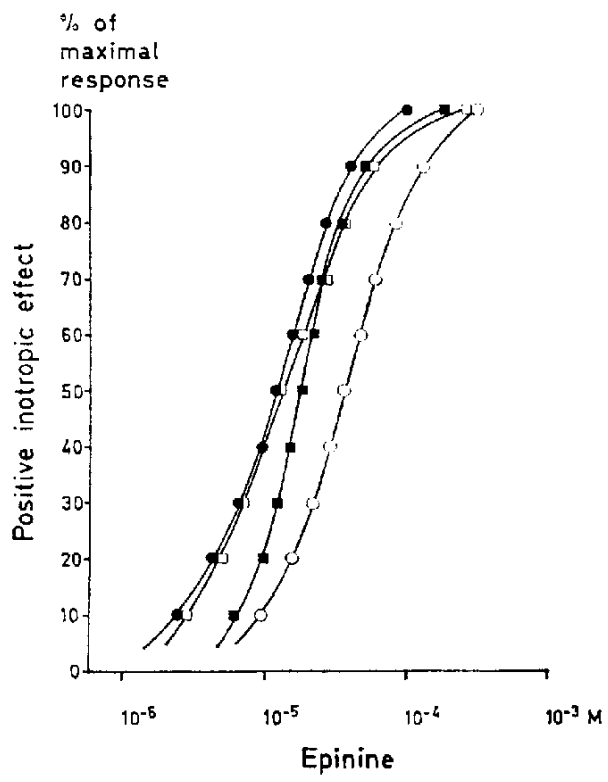

Fici. 4. The positive inotropic effect of epinine on the isolated rabbil papillary muscle. - - control $(n=22)$ : $\square$ : phentolaminc $10^{-6} \mathrm{M}(\mathrm{n}=10) ;[\rceil-[$ : prindolol $10^{-5} \mathrm{M}(\mathrm{n}=12) ; 0-($ : phentolamine : prindolol $(n-22)$.

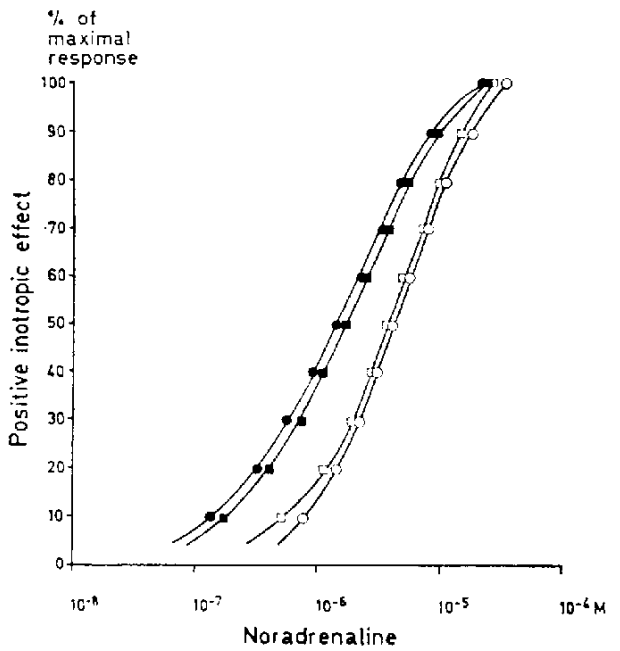

Fici. 6. The positive inotropic effect of notadrenaline on the isolated rabbit papillary muscle. - introl $(n-10)$; $\mathbf{D}-$ phentolamine $10^{-6} \mathrm{M}(\mathrm{n}-6) ;, 1-[\mathrm{b}$ : prindolol $10^{-4} \mathrm{M}(\mathrm{n}=5)$; . - : phentolamine prindolol $(n=-11)$. 


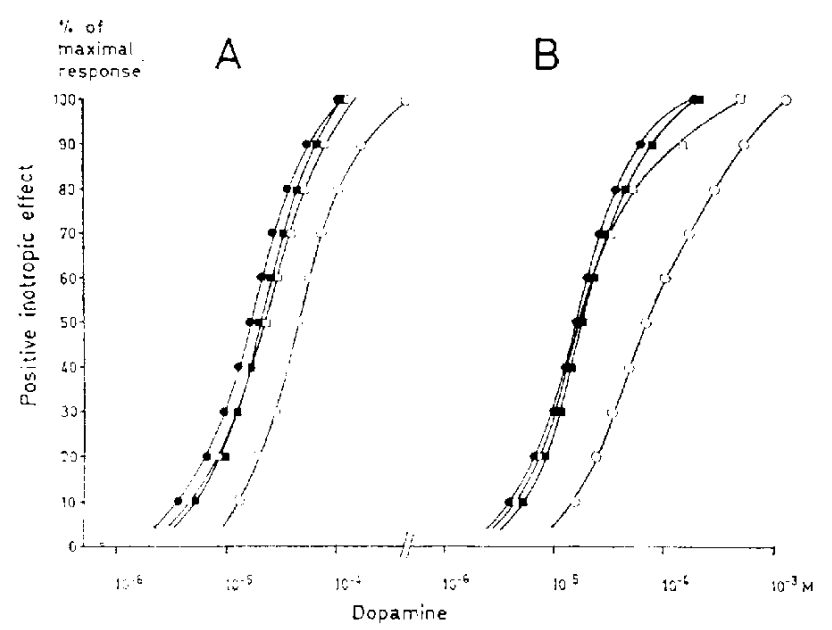

$\mathrm{F}_{\mathrm{IG}}$. 7. The positive inotropic effect of dopamine on the rabbit papillary muscle isolated from non-treated $(A)$ and reserpine-pretreated $(B)$ animals.

control $(\mathrm{n}=-7$ and 8 in $\mathrm{A}$ and $\mathrm{B}$, respectively);

D- phentolamine 10 : $\mathrm{M}$ ( $\mathrm{n}=-3$ and 4): 1 : prindolol $10^{-5} \mathrm{M}$ (n-4 each); :-.. : phentolamine + prindolol $(n-7$ and 8$)$.

shifted the dose-response curve for noradrenaline to the same extent in the absence and in the presence of phentolamine. Phentolamine did not affect the curve for noradrenaline even in the presence of prindolol. The dose-response curve for dopamine was not changed by phentolaminc or prindolol alone. Phentolamine in the presence of prindolol and vice versa shifted the whole curve for dopamine to the right. Reserpine-pretreatment did not affect the dose-response curve for dopamine. In reserpinized preparations, prindolol did shift the upper part of the curve (Fig. 7B). The shift evoked by phentolamine in the presence of prindolol and ice versa was greater in the papillary muscle pretreated with reserpine than in preparations from non-treated animals.

Since the maximal responses to sympathomimetic amines were not alfected by phentolamine and/or prindolol, the $a$ - and 3 -stimulating effect of amines was analyzed quantitatively

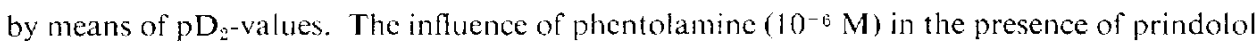
$\left(10^{-8} \mathrm{M}\right)$ is shown in Table 2. The difference of the $\mathrm{pD}_{2}$-value before and after the addition of phentolamine was calculated as $J \mathrm{pD}_{2}$-value. These values are assumed to represent the affinity to the $\alpha$-adrenoceptors. The order of affinities for the amines tested was the following: phenylcphrine $\left(\mathrm{JpD} \mathrm{p}_{2}\right.$-value $\left.=1.12\right)>$ norfenephrine $(0.77)$ synephrine $(0.63) \cdots$ adrenaline $(0.41)$ >epinine $(0.37)>$ dopamine $(0.31)>$ noradrenaline $(0.13)$. The difference of the $\mathrm{DD}_{2}$-value for noradrenaline was not significant.

The influence of prindolol $\left(10^{-8} \mathrm{M}\right)$ in the presence of phentolamine $\left(10^{-6} \mathrm{M}\right)$ is shown in Table 3. The JPD -values, the difference of the $\mathrm{pD}_{2}$-value before and after the addition of prindolol, were rather consistent lor all amines. They were in the range trom 0.34 (epinine) to 0.57 (adrenaline and phenylephrine). A three times higher concentration of phentolamine, $3 \because 10^{-6} \mathrm{M}$, did not affect further the $\mathrm{pD}_{2}$-values for the amines as has been shown for phenyl- 
TABLE 2. Influence of phentolamine ( $\left.10^{-6} \mathrm{M}\right)$ on the positive inotropic effect of sympathomimetic amines in the presence of prindolol $\left(10^{-5} \mathrm{M}\right)$

\begin{tabular}{|c|c|c|c|c|}
\hline \multicolumn{5}{|c|}{$\mathrm{pD}_{2}$-value } \\
\hline & n & & Prindolol & $J p D_{2}$-value \\
\hline & & & Phentolamine & \\
\hline Adrenaline & 6 & $5.85 \cdots 0.15$ & $5.43 \therefore 0.08$ & $0.41-0.09 *$ \\
\hline Phenylephrine & 8 & $5.82: 0.10$ & $4.71 \cdot 0.05$ & $1.12-0.09^{* * *}$ \\
\hline Synephrine & 4 & $4.43 \quad 0.05$ & $3.81 \cdots 0.04$ & $0.63 \ldots 0.12^{*}$ \\
\hline Epinine & 12 & $4.93 \because 0.08$ & $4.56 \div 0.05$ & $0.37: 0.03^{* *}$ \\
\hline Noradrenaline & 5 & $5.48 \quad 0.13$ & $5.35 \div 0.09$ & $0.13-1-0.091$.s. \\
\hline Norfenephrine & 5 & $5.01 \cdot 0.11$ & $4.24: 0.09$ & $0.77-0.06^{* *}$ \\
\hline Dopamine & 4 & $4.67+0.06$ & 4.360 .01 & $0.31-0.06^{*}$ \\
\hline
\end{tabular}

$* P>0.05 ; \quad * * P 0.001 ; \quad$ n.s. $=-$ not significant.

TABLE 3. Influence of prindotol $\left(10^{-5} \mathrm{M}\right)$ on the positive inotropic effect of sympathomimetic amines in the presence of phentolamine $\left(10^{-6} \mathrm{M}\right)$

\begin{tabular}{|c|c|c|c|c|}
\hline \multicolumn{5}{|c|}{$\mathrm{pD}_{2}$-valtue } \\
\hline & \multirow[t]{2}{*}{$n$} & \multirow[b]{2}{*}{ Phentolamine } & \multirow{2}{*}{$\begin{array}{l}\text { Prindolol } \\
\cdot-\cdot \\
\text { Phentolamine }\end{array}$} & \multirow{2}{*}{$J \mathrm{pD}_{2}$-value } \\
\hline -.... & & & & \\
\hline Adrenaline & 7 & $5.93 \cdot 0.08$ & $5.37 \pm 0.08$ & $0.56 \div 0.05^{* * *}$ \\
\hline Phenylephrine & 6 & $4.73,0.09$ & $4.16 \div 0.10$ & $0.57 \therefore 0.10^{* *}$ \\
\hline Synephrine & 8 & $4.41 \cdot 0.07$ & $4.02-0.05$ & $0.40=0.04^{* * *}$ \\
\hline Epinine & 10 & $4.74-0.04$ & $4.40: 0.08$ & $0.34: 0.06^{* * *}$ \\
\hline Noradrenaline & 6 & 5.83 .0 .12 & $5.46-0.09$ & $0.37=0.05^{* x: *}$ \\
\hline Norfenephrine & 5 & $4.77 \div 0.14$ & $4.37 \quad 0.13$ & $0.41 \leq 0.04^{* * *}$ \\
\hline Dopamine & 3 & $4.71-1 \cdot 0.04$ & $4.35 . \pm 0.03$ & $0.36=0.05^{*}$ \\
\hline
\end{tabular}

$* \mathrm{P} .0 .05 ; \quad * * \mathrm{P}<0.005 ; * * * \mathrm{P}, 0.001$

phrine in the previous study (16). In addition, the shift of the dose-response curve in the presence of $3 \times 10^{-8} \mathrm{M}$ prindolol amounted to twice that obtained with $10^{-8} \mathrm{M}$ (not shown). Therefore, the $\mathrm{pD}_{2}$-value in the presence of phentolamine almost exclusively represents the affinity to $\beta$-adrenoceptors. Thus, the order of affinities for amines to $\beta$-adrenoceptors was: adrenaline $\left(\mathrm{pD}_{2}\right.$-value $\left.=5.93\right)$ noradrenaline $(5.83)>$ norfenephrine $(4.77)=$ phenylephrine $(4.73)=$ epinine $(4.74)$ - dopamine $(4.71)$ - synephrine (4.41).

Influence of the blockade of neuronal and exiraneuronal uptake of amines

Table 4 shows the $\mathrm{pD}_{2}$-value for four amines in the preparation in which the neuronal and extraneuronal uptake of amines was blocked by cocaine $\left(3.10^{-5} \mathrm{M}\right)$ and corticosterone (4 $10^{-5} \mathrm{M}$ ), respectively. The affinities for these amines were increased signficantly: the cardiac transmitter, noradrenaline, was enhanced the most $(0.94 \log$ units $)$ and now had the highest affinity. In these preparations the blocking effects of phentolamine (Table 5A) on norfenephrine and phenylephrine were greater. Furthermore, the effect of noradrenaline was significantly ( $P$. 0.05) blocked by phentolamine ( $T$ able $5 A$ ). The blocking effects of prindolol remained in the same range $(0.33$ to 0.50$)$ in these preparations (Table $5 \mathrm{~B}$ ). 
TABLE 4. Influence of the blockade of the neuronal and extrancuronal uptake of amines by cocaine $\left(3 \therefore 10^{-5} \mathrm{M}\right)$ and corticosterone $\left(4 \times 10^{-5} \mathrm{M}\right)$, respectively, on the $\mathrm{pD}_{2}$-values of sympathomimetic amines

\begin{tabular}{lcc}
\hline & Control & Cocaine + corticosterone \\
Adrenaline & $6.18 \ldots 0.09(14)^{*}$ & $6.41+0.08(11)$ \\
Phenylephrine & $5.77 \ldots 0.06(28)$ & $6.06 \ldots 0.09(14)$ \\
Noradrenaline & $5.91 \ldots 0.09(10)$ & $6.85+0.05(24)$ \\
Norfenephrine & $5.17 \ldots 0.09(10)$ & $5.58 .10 .05(12)$ \\
\hline
\end{tabular}

* Number of experiments in brackets. All values in the presence of cocaine and corticosterone are significantly different from the control values $(P<0.05)$.

TARL 5. Influence of cocaine $(3 \div 10: \mathrm{M})$ and corticosterone $\left(4: 10^{-5} \mathrm{M}\right)$ on the blocking effect of phentolamine $10^{-6} \mathrm{M}(\mathrm{A})$ and of prindolol $10^{-5} \mathrm{M}(\mathrm{B})$

(A) Effect of phentolamine in the presence of prindolol

\begin{tabular}{|c|c|c|c|c|}
\hline & \multirow[b]{2}{*}{$n$} & \multicolumn{2}{|c|}{$\mathrm{pD}_{2}$-value } & \multirow[b]{2}{*}{$J \mathrm{pD}_{2}$-value } \\
\hline & & Prindolol & $\begin{array}{l}\text { Prindolol } \\
\div- \\
\text { Phentolamine }\end{array}$ & \\
\hline Adrenaline & 8 & $6.09 \div 0.14$ & $5.79: 0.11$ & $0.31=0.06$ \\
\hline Phenylephrine & 5 & $5.77: 0.12$ & $4.36-1.11$ & $1.41-0.18$ \\
\hline Noradrenaline & 8 & $6.52-0.07$ & $6.27 \pm 0.07$ & $0.24-0.03$ \\
\hline Norfenephrine & 6 & $5.71-0.06$ & $4.45 \pm 0.05$ & $1.26 \pm 0.06$ \\
\hline
\end{tabular}

(B) Effect of prindolol in the presence of phentolamine

\begin{tabular}{|c|c|c|c|c|}
\hline \multicolumn{5}{|c|}{$\mathrm{pD}_{2}$-value } \\
\hline & \multirow[t]{2}{*}{$n$} & \multirow[b]{2}{*}{ Phentolamine } & Prindolol & $1 p D_{2}$-valuc \\
\hline & & & Phentolamine & \\
\hline Adrenaline & 7 & $6.24: 0.07$ & $5.90-0.05$ & $0.33 \ldots 0.05$ \\
\hline Phenylephrine & 9 & $4.93 \div 0.14$ & $4.43+0.05$ & $0.50-0.07$ \\
\hline Noradrenaline & 8 & $6.64-0.08$ & $6.28 \perp 0.06$ & $0.36 \div 0.02$ \\
\hline Norfenephrine & 6 & $5.03 \therefore 0.10$ & $4.53 \div 0.05$ & $0.50-0.04$ \\
\hline
\end{tabular}

\section{Relationship between the structure of amines and $\alpha$-adrenoceptor stimulating activity}

Fig. 8 gives the structural relations among phenylephrine, adrenaline, noradrenaline and norfenephrine, in which the para-hydroxyl group (p-OH) of the benzene ring and the $\mathrm{N}$-methyl group $\left(\mathrm{N}-\mathrm{CH}_{3}\right)$ make the structural differences. Phenylephrine and norfenephrine which have no $\mathrm{p}-\mathrm{OH}$ in the benzene ring had about $0.6 \log$ units higher affinities to $\alpha$-adrenoceptors than did adrenaline and noradrenaline which both possess the p-OH. Adrenaline and phenylephrine had about $0.3 \log$ units higher affinities than the demethylated compounds, notadrenaline and norfenephrine. These relationships exist still under the blockade of neuronal and extraneuronal uptake of amines, though the intluence of $N$ methyl substitution became less and that of $\mathrm{p}-\mathrm{OH}$ substitution was greater (Fig. 8). 


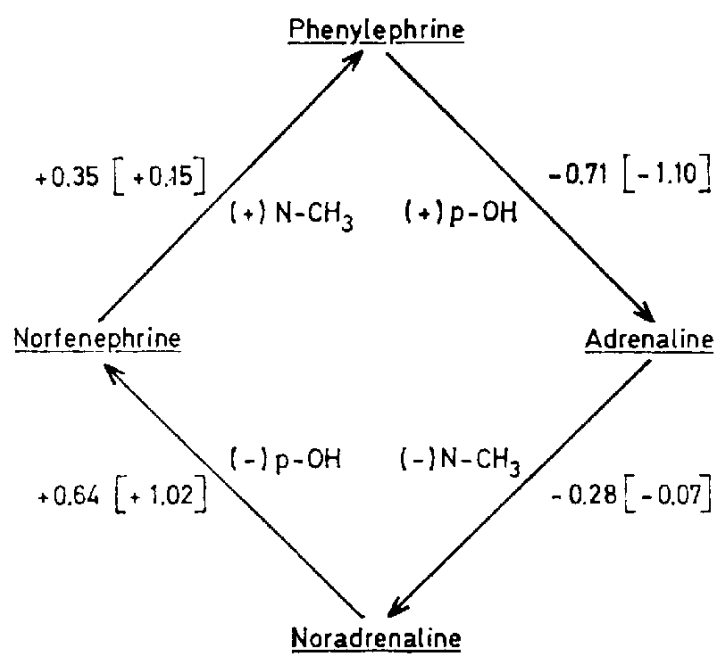

Fig. 8. The structural relationships among phenylephrine, adrenaline, noradrenaline and norfenephrine, and the difference of their relative potencies 10 induce the positive inotropic effect via $\alpha$-adrenoceptors. Arrows between two amines indicate the substitution ( - ) or subtraction ( - ) of p-OH or $\mathrm{N}_{-} \mathrm{CH}_{3}$ groups. Factors in logarithmic units are calculated from the $J \mathrm{pD}_{2}$-value in Table 2 ; - - r-means the increase or decrease, respectively, of the affinity. Figures in the brackets show the factor calculated from the preparations after blockade of the neuronal and extrancuronal uptake of amines (Table 5).

\section{DISCUSSION}

The relative potencies for seven sympathomimetic amines to induce the positive inotropic effect on the isolated papillary muscle of the rabbit were compared by determining doseresponse curves. Since the relative potencies of agonists will be the same as their relative affinities for a given type of receptor when their intrinsic activities are equal (23), the intrinsic activities of the amines were determined. Adrenaline, noradrenaline, epinine and dopamine had a similar intrinsic activity to that seen with isoprenaline, but those for synephrine, norfenephrine and phenylephrine were lower than that for isoprenaline. Therefore, in the present study the relative potencies of only adrenaline, noradrenaline, dopamine and epinine could be compared by their relative affinities.

The influence of the blockade of anine uptake mechanisms was also investigated, as the relative potencies depend not only on the affinity to adrenoceptors but also on mechanisms of inactivation in the case of sympathomimetic amines (24). When the neuronal and extraneuronal uptake of amines was blocked by cocaine and corticosterone, respectively, relative affinities to adrenoceptors were: noradrenaline $>$ adrenaline, phenylephrine $>$ nofenephrine > epinine dopamine synephrine. Up to the last few years it has generally been accepted that the positive inotropic effect of sympathomimetic amines is mediated solely by a-adrenoceptors, but not by atadrenoceptors (25). Recent findings on the isolated rabbit papillary muscle, howcver, show that the positive inotropic effect of phenylephrine and adrenaline (16) as well ats those of methoxamine and naphazoline (17) were antagonized 
by the a-adrenoceptor blocking agent phentolamine. Such is consistent with observations of other authors $(1-7,12)$. In the present study it was further shown that the positive inotropic effect of norfenephrine, synephrine, epinine and dopamine were also partly mediated by $\alpha$-adrenoceptors. Although the positive inotropic effect of noradrenaline was not influenced at all by phentolamine in the more physiological conditions, it was significantly affected by phentolamine when the neuronal and extraneuronal uptake of amines was blocked. We conclude, therefore, that noradrenaline stimulates a-adrenoceptors also in the papillary muscle to catuse positive inotropic effects, but that this effect is very weak and only detciable under the blockade of amine uptake mechanisms.

Thus, it became evident that the overall potencies of sympathomimetic annines sufficient to produce a positive inotropic effect on the rabbit papillary muscle depend both on, $;-$ and $a$-adrenoceptors. This means that in order to study one type of adrenoceptor in this preparation, the other must be blocked as previously postulated by Furchgott (18), because both types interact. In the case of dopamine this interaction is mosi prominent: dopamine may induce the positive inotropic effect through both types of adrenoceptors in the same dose range. Therefore, when one type of adrenoceptor is blocked, the other can compensate: in the presence of an $a$ - or s-adrenolytic drug, all dopamine molecules can act on the other type of adrenoceptors having almost the same affinity for dopamine, whereby dopamine induess the same extent of inotropic effect. Reserpine-pretreatment, which abolished the positive inotropic effect of tyramine in the present preparations, did not affect the positive inotropic effect of dopaminc. In these preparations prindolol shifted the upper part of the dose-response curve for dopamine 10 the right even in the absence of phentolamine indicating that dopamine released noradrenaline in relatively higher concentrations, however, the main part of the dose-response curve for dopamine was due to its direct action. Observations that on the reserpine-pretreated preparations, the dose-response curve for dopamine was displaced more prominently by simultaneous application of phentolamine and prindolol than in non-treated preparations, and that the slope of the curve became more gentle under thesc conditions ( Fig. 7B) can also be ascribed to the indirect action of dopamine. Thus, dopamine produced its positive inotropic action on the rabbit papillary muscle through three components: the direct $\alpha$, and $\beta$ - adrenoceptor stimulation and the indirect ,3-adrenoceptor stimulation via the release of noradrenaline. As has been stated above, the direct action of dopamine was predominant enough to compose the main part of the doseresponse curve and the indirect action was weak and distinguishable only in the presence of both kinds of adrenolvic drugs: in the reserpine-pretreated preparations prindolol can occupy more B-adrenoceptors than in the non-treated preparations because of the absence of indirectly released noradrenaline. The $\alpha$ - as well as, j-adrenoceptor stimulating activitics for dopanine equalled those for epinine when they were compared as pDe-valuss. The difference between the effects of epinine and dopamine was that epinine stimulated a-adrenoceptors at lower concentrattons and, f-receptors at higher concentrations whereas dopamine stmulated both receptors in the same dese range.

raking the intrinsic activity and the alfinity in the presence of phentolamine under the 
blockade of amine uptake mechanisms into consideration, the relative potencies to induce the positive inotropic effect ria, s-adrenoceptors were the following: noradrenaline $>$ adrenaline, cpinine = dopamine norfenephrine = phenylephrine synephrine. Thus the relationships between the structure and activity to stimulate $\beta$-adrenoceptors in the papillary muscle are quite consistent with previous findings (24,25): (1) Absence of one of the hydroxyl groups in 3 (meta-) or 4 (para-) positions of the benzene ring reduces the overall potency; (2) Substitution of an $\mathrm{OH}$-group on the $j$-carbon atom of the side chain increases the potency.

Concerning the restionship between the structure and the $a$-adrenoceptor stimulating activity, it seems that $a$-adrenoceptors in the heart have a nature somewhat different from those of other organs. Consistent with the previous observation $(24,25)$ is that $\mathrm{N}$-methylation increases the potency: adrenaline noradrenaline; phenylephrine norfenephrine. The difference between dopamine and epinine was not evident. This may be due to their relatively lower affinities to adrenoceptors by lacking the OH-group on the $\beta$-carbon atom. Although the intrinsic activities for amines were decreased when one of the OH-groups in 4 or 3 positions was absent, the $\alpha$-adrenoceptor stimulating activities were more pronounced: phenylcphrine $>$ adrenaline; norfenephrine, noradrenaline; synephrine $>$ adrenaline. In particular, the subtraction of the $\mathrm{OH}$-group in 4 position from noradrenaline to norfenephrine as well as from adrenaline to phenylephrine caused an increase of affinities to the same degree (Fig. 8).

Furthermore, it should be noted that phentolamine shifted the lower part of the doseresponse curves for sympathomimetic amines, while prindolol, the upper part. This means that these amines cause the positive inotropic effect through a-adrenoceptors, when they are administrated in a lower concentration. The intrinsic activities for $a$-sympathomimetic amines to induce the positive inotropic effect are lower than those for sympathomimetic amines, and the a-adrenoceptor stimulation is accompanicd by the j-adrenoceptor stimulation when the concentration becomes higher. Furlhermore, since the vasoconstriction induced by $a$-sympathomimetic amines is predominant, their effects on cardiac contraction were more or less ignored. However, since all amines tested had a stimulating action on $a$-adrenoceplors in the heart and their cffects were induced without any changes in the heart rate (13), a-adrenoceptor stimulating actions of these amines on the heart may be also favorable for the treatment of the cardiogenic shock or hypotensive states of various origin. It would be worthwhile, therefore, to reconsider the applicability of these sympathomimetic amines in such cases as mentioned above, and to re-evaluate the participation of the positive inotropic effect mediated by a-adrenoceptors for the therapeutic use of sympathomimetio amines.

Recently, it became evident that the positive inotropic effect ria a-adrenoceptors is induced through a biochemical process different from that via $\beta$-adrenoceptors: during the induction of the positive inotropic effect via atadrenoceptors the elevation of the level of cyclic AMP which was obserted alfer fadrensecentor stimulation did not occur (26); the effect rat a-idtenowptors was more sensitive to the change of temperature latan that ria, radrenoceptors: the cakcium antagonistic drug 19600 influenced more markedly 
the effects induced via $\alpha$ - than via $\beta$-adrenoceptors (27); the effect produced va $\alpha$-adrenoceptors were strongly dependent on the frequency of stimulation (17).

The physiological importance of the second way to stimulate cardiac contractility via $\alpha$-adrenoceptors cannot be evaluated at the moment. In this connection, however, we would like to draw attention to the fact that the biogenic annine and cardiac transmitter, noradrenaline, does stimulate the contractility only via, s-adrenoceptors, whereas the biogenic amine and adrenal medullary hormone, adrenaline, which is released in cases of emergency, can stimulate cardiac contractility both via $\alpha$-and, 3 -adrenoceptors. In this way adrenaline is very likely capable of mobilizing the maximal contractile capacity of the heart.

\section{REFERENCES}

1) GOVIer, W.C.: Life Sci. 6, 1361 (1967)

2) Govier, W.C. . J. Pharmacol. exp. Ther. 159, 82 (1968)

3) Benfey, B.G. a\d Carolin, T.: Canad. J. Physiol. Pharmacol. 49, 508 (1971)

4) Benfey, B.G. And Varma, D.R.: Brit. J. Pharmacol. 30, 603 (1967)

5) Parr, J.J. and Urquilla, P.R.: Europ. J. Pharmacol. 17, 1 (1972)

6) Benfey, B.G.: Brit. J. Pharmacol. 48, 132 (1973)

7) Nakashima, M., Tsuru, H. ayd Shtgel, T.: Japan. J. Pharmacol. 23, 307 (1973)

8) Yoo, C.S. A.vd Lee, W.C.: J. Pharmacol. exp. Ther. 172, 274 (1970)

9) Wagner, J. And Schimann, H.J.: Arch. Pharmacol. 277, R 86 (1973)

10) Wagnier, J. and Reinilardot, D.: Arch. Pharmacol. 282, 295 (1974)

11) WeNzel, D.G. A.ND SLi, J.L.: Archs int. Pharmacodyn. Thér. 160, 379 (1966)

12) Starke, K.: Arch. Pharmacol. 274, 18 (1972)

13) Wagner, J. Endoh, M. And Reivhardt, D.: Arch. Pharmacol. 282, 307 (1974)

14) Weston, A.H.: Brit. J. Pharmacol. 43, 593 (1971)

15) Kabela, E., Jalife, J., Peon, C., Cros, L. and Mendez, R.: Archs imt. Pharmacodyn. Thirr. 181, $328(1969)$

16) Schümann, H.J., Endoh, M. And Wagne:, J.: Arch. Pharmacol, 284, 133 (1974)

17) Endoh, M. And Schumanx, H.J.: Arch. Pharmacol. 287. 377 (1975)

18) Furchgott, R.F.: Fedin Pioc. 29, 1352 (1970)

19) Reinhardt, D. and Wagner. J.: Arch. Pharmacol. 284, 245 (1974)

20) Starke, K., Montel, H., Gayk, W. and Merker, R.: Arch. Pharmacol 285, 133 (1974)

21) Ariëns, E.J. : Mol. Pharmacol. Vol. 1, p. 145, Academic Press, New York and London (1964)

22) Van Rossum, J.M.: Archs int. Pharmacodyn. Therr. 143, 299 (1963)

23) FurchGott, R.F.: Handbook of Experimental Pharmacology, Edited by BlaschKo. H. AND Muscholl, E. Vol. 33, p. 289, Springer-Verlag, Berlin, Heidelberg and New York (1972)

24) Trendelenburgi, U.: Handbook of Experimetital Pharmacology, Edited by Blaschko, $\mathrm{H}$. AND Muscholl, E. Vol. 33, p. 342, Springer-Verlag, Berlin, Heidelberg and New York (1972)

25) INNtS, I.R. AND Nicktrson, M.: The Pharmacological Basis of Therapuaties (Fourth cedition), Edited by Goodman, L.S. ANd Gilman, A.. p. 478, Macmillan Co.. New York (1970)

26) Schimann, H.J., ENDOH, M. AND BrodDe, O.F.: Arch. Pharmacol. 289, 291 (1975)

27) EVDOH, M., Wagiver, J. AND SCHI'MANi, H. J.Arch. Pharmacol. 287, 61 (1975) 